\title{
Análisis turístico de Almadén (Ciudad Real). Propuestas de mejora en un entorno Patrimonio de la Humanidad
}

\author{
Alberto Azuara Grande \\ Universidad Rey Juan Carlos, Madrid \\ albertoagrande@gmail.com \\ Isabel del Río de la $\mathrm{Hoz}$ \\ Universidad Rey Juan Carlos, Madrid \\ isabel.delrio@urjc.es
}

Recibido: 17-11-2015

Aceptado: 28-03-2016

Keywords: Mining tourism; World Heritage; Almadén; territorial development

\section{ABSTRACT}

Tourism Analysis of Almaden (Ciudad Real). Improvement proposals in a UNESCO World Heritage Site environment In recent decades it has been attending a steady increase in the importance of cultural tourism in our country and in the rest of Europe, considering as an alternative model to the traditional "sun and beach tourism". This "indoor" tourism takes different positions depending on the destination to visit, tourist motivation or selected type of tourism, thus resulting different possibilities of tourism, provided through urban destinations of cultural tourism, nature tourism or rural tourism, roughly. These forms of tourism are not independent, and can be displayed in combination forming large touristic areas, and may contain innovative products such as the case of cultural tourism related to industry and mining elements. In these territories it has managed to recapture the industrial and mining heritage, accompanied by introducing tourism as an element capable of helping the development of the area. The case of Almadén is paradigmatic in Spain, due to its recent declaration as a World Heritage Site, hence it is necessary to assess what is the current situation on the place, what has been done so far, and based on this, to be carried forward from planning and tourism management in order to continue the development and consolidation of destination, without losing sight of the elements of authenticity and integrity imposed by UNESCO.

Palabras clave: Turismo minero; Patrimonio Mundial; Almadén; desarrollo territorial

\section{RESUMEN}

Venimos asistiendo en las últimas décadas a un incremento continuado de la importancia del turismo cultural tanto en nuestro país como en el resto de Europa, planteándose como un modelo alternativo al tradicional "turismo de sol y playa". Este turismo "de interior" toma distintas posiciones dependiendo del destino a visitar, motivación del turista o tipo de oferta turística seleccionada, surgiendo así diferentes posibilidades de oferta turística, proporcionada a través de destinos de turismo cultural urbano, turismo de naturaleza o de turismo rural, a grandes rasgos. Estas formas de turismo no resultan independientes entre sí, y pueden mostrarse en combinación formando amplios espacios territoriales turísticos, pudiendo contener productos $\mathrm{y}$ elementos más innovadores como son el caso de las acciones de desarrollo del turismo cultural relacionado con la industria y la minería. En estos territorios se ha conseguido recuperar el patrimonio industrial y minero, acompañado de la implantación de oferta turística como elemento capaz de 
contribuir a desarrollar la zona. El caso de Almadén es paradigmático en España, debido a su reciente declaración como Patrimonio de la Humanidad, de ahí que sea necesario evaluar cuál es la situación en la que se encuentra actualmente el lugar, qué es lo que se ha venido haciendo hasta ahora, y en base a esto, qué debe realizarse en adelante desde la planificación y la gestión turística para continuar en el desarrollo y consolidación del destino, sin perder de vista los elementos de autenticidad e integridad recogidos por la UNESCO

\section{INTRODUCCIÓN}

\subsection{Contextualización}

Parece demostrarse que con el paso del tiempo la industria turística sigue reconvirtiéndose y ampliándose, yendo más allá de los destinos de costa y de la oferta cultural de las ciudades. Así pues, han venido surgiendo en las últimas décadas en nuestro país pequeños destinos turísticos estructurados en torno a amplios territorios rurales que están haciendo del turismo un elemento de desarrollo social y económico para las poblaciones locales, que generalmente cuentan con mayores problemas de desarrollo.

En este ámbito se enmarcan las acciones de desarrollo del turismo minero, implantado en territorios que por lo general han quedado en declive tras llevarse a cabo un proceso de desindustrialización y por consiguiente, acompañados de problemas económicos y sociales. Uno de los lugares de España donde se dieron estas circunstancias fue Almadén, que tras el progresivo abandono de las actividades mineras y metalúrgicas, finalmente se apostó por emprender un proceso de recuperación y puesta en valor del histórico patrimonio minero e industrial, en torno al cual se ha venido creando diversos elementos para la implantación del sector turístico como elemento dinamizador del territorio. En este sentido, Almadén cuenta con el añadido de que su patrimonio minero relacionado con el mercurio, ha sido reconocido como Patrimonio Mundial por la UNESCO en 2012, lo que le dota de un de un elemento más de complejidad en el desarrollo, pero a la vez un abanico de nuevas posibilidades.

Es por tanto, esta nueva situación de Almadén, así como las convicciones referidas anteriormente respecto a la recuperación del patrimonio y su puesta en valor turística en complemento con una infraestructura turística sólida como elemento dinamizador del territorio, las que hacen que se haya seleccionado Almadén como objeto de estudio de este trabajo.

\subsection{Trabajos previos}

La extracción del mineral de cinabrio y el mercurio en Almadén ha resultado prácticamente ininterrumpida a lo largo de los últimos dos mil años, por tanto, es comprensible que en un periodo histórico tan amplio los acontecimientos históricos acerca de estas minas, hayan sido muy numerosos y de enorme interés para los investigadores de diferentes épocas. Es por ello, que para hacer una descripción histórica de las minas, como es el caso de este trabajo, se recurra a volúmenes recopilatorios de los acontecimientos producidos hasta el siglo XIX (Matilla Tascón A., 1958, 1987), y otras publicaciones complementarias (Lang M., 1994); (López Morrell M.A., 2009); (Carrasco Milara F.J., 2009), ya que no existe un único volumen recopilatorio para la época posterior al año 1800. De este modo, durante el análisis histórico se detallan los periodos y acontecimientos más importantes surgidos en las Minas de Almadén desde su origen romano hasta la actualidad, algo necesario para comprender la importancia histórica de este enclave minero, y cómo gracias a ello son posibles tanto el reconocimiento de su patrimonio como la actividad turística incipiente. 
Tras este análisis histórico, se procede a establecer el estado de la cuestión acerca de las investigaciones y publicaciones sobre el turismo minero e industrial y su evolución en España y en Europa, entre las que se incluyen investigaciones sobre Almadén, especialmente las realizadas por Cañizares M.C., entre otros autores. En ellas, se hace referencia a numerosos aspectos de los procesos de puesta en valor del patrimonio minero, detallando también las características de la declaración de Patrimonio Mundial por la UNESCO en otras publicaciones específicas. Por último, se revisan publicaciones relacionadas con la gestión turística de los sitios patrimonio Mundial en Europa y también en España, como es el caso de las Ciudades Patrimonio de la Humanidad españolas, referente en nuestro país a la hora de coordinar acciones de comercialización y promoción del patrimonio (García Hernández, 2007).

\section{OBJETIVOS DE LA INVESTIGACIÓN}

Los principales objetivos para el trabajo se corresponden fundamentalmente con la elaboración de un análisis exhaustivo de la actividad turística actual de Almadén desde distintos puntos de vista que permitan obtener un diagnóstico general del destino, a partir del cual se puedan detectar las debilidades, amenazas, fortalezas y oportunidades existentes actualmente. A su vez, este diagnóstico acerca de la situación del destino tiene el objetivo de definir líneas estratégicas a seguir para mejorar el desarrollo turístico en Almadén, a partir de las cuales se realizan propuestas concretas de actuación para llevarlas a cabo sobre el destino. Éstos son los últimos e imprescindibles objetivos a conseguir, y por los que se ha decidido llevar a cabo este trabajo, ya que la realización del análisis y el diagnóstico sin la elaboración de propuestas de actuación en el destino a partir de estrategias generales dejaria un proyecto incompleto, que no cumpliría con la principal función del trabajo, es decir, la búsqueda de soluciones que permitan mejorar el desarrollo turístico del destino.

\subsection{Objetivos especificos}

A continuación se especifican los objetivos concretos que se pretenden desarrollar en la elaboración del trabajo, los cuales servirán de sustento para alcanzar los objetivos generales planteados:

- Comprender la riqueza histórica, cultural y patrimonial que ha llevado a Almadén a ser declarado como Patrimonio de la Humanidad, así como las relaciones y la vinculación que han tenido, tienen y tendrán estos elementos en el desarrollo turístico del destino.

- Establecer una valoración crítica y objetiva acerca de los recursos turísticos, servicios, infraestructuras y oferta turística existentes en el destino.

- Detectar los perfiles de la demanda turística en el destino.

- Conocer las principales actuaciones turisticas desarrolladas en el destino y su entorno en materia de gestión, promoción y comercialización turística.

- Detectar los principales agentes turísticos que intervienen en el destino y sus funciones, verificando cuáles son las relaciones existentes entre los mismos.

\section{METODOLOGIA}

En cuanto a la metodología seguida para la realización de este trabajo, ha sido dividida en seis fases principales según los procesos en los que se ha ido desarrollando la investigación:

- La primera fase consistió en la búsqueda y selección de la bibliografia histórica y científica acerca del destino, realizada principalmente a través de diferentes bases de datos de publicaciones. Asimismo, se realizaron consultas en diferentes páginas web 
relacionadas con el destino y con contenidos de interés para la investigación. Toda la información obtenida fue filtrada y clasificada según sus contenidos.

-En la segunda fase se seleccionaron las fuentes de información y sus correspondientes herramientas para la recogida de datos. De esta forma, se escogieron fuentes de información primarias, a partir de entrevistas en profundidad que se realizaron a los dos principales agentes turísticos del destino (Parque Minero y Concejalía de Turismo), los cuestionarios al resto de agentes y las fichas de los recursos turísticos existentes. En cuanto a las secundarias, al margen de la bibliografia, se obtuvo información del INE y del IGN, entre otras informaciones facilitadas por otras instituciones.

- La tercera fase consistió en la realización del trabajo de campo sobre el destino, siendo necesario trasladarse a Almadén durante tres dias para obtener información de primera mano sobre los recursos turísticos y la oferta turística mediante su visita. Se realizaron las entrevistas en profundidad y algunos de los cuestionarios, se obtuvieron los folletos e información turística del destino para su análisis, y se tomaron numerosas fotografias para complementar la investigación.

-Durante la cuarta fase, se fue procesando toda la información recogida en el trabajo de campo, mediante la transcripción de las entrevistas en profundidad, la clasificación según las respuestas obtenidas en los cuestionarios, así como la organización del propio material gráfico y estadístico. Por otro lado, se procedió a completar el modelo de fichas de recursos turísticos con la información obtenida, siguiendo un proceso metodológico específico para facilitar la comprensión del contenido.

- En la quinta fase se procedió a analizar todos los resultados obtenidos durante la investigación, a través de la separación en apartados y epígrafes la información del trabajo. Se crearon tablas y gráficos además del acompañamiento de imágenes para facilitar la comprensión del propio análisis. Igualmente, para el análisis de las relaciones entre agentes, se procedió a seguir una metodología específica para dicho análisis, en el que se empleó el programa informático Ucinet 6.0.

- Por último en la sexta fase, con todo el análisis realizado se procedió a completar un análisis DAFO para mostrar el diagnóstico obtenido del destino, con el fin de establecer estrategias y propuestas de mejora. Finalmente, se revisó todo el contenido del trabajo y se realizaron las correcciones oportunas antes de cerrar la investigación.

\section{ANÁLISIS DEL DESTINO}

Seguidamente, se creyó conveniente realizar un análisis del entorno próximo de Almadén, es decir, su provincia (Ciudad Real) y comunidad autónoma a la que pertenece (Castilla-La Mancha). Para ello, se tuvieron en cuenta una serie de factores socioeconómicos, culturales, naturales y tecnológicos que permiten establecer un diagnóstico de la situación en la que se encuentra el entorno, y cómo puede afectar positivamente o de forma negativa al desarrollo turistico del destino.

\subsection{Análisis socioeconómico del destino}

Respecto al análisis interno del propio destino, se comenzó por realizar una valoración de la situación socioeconómica del lugar, ya que en buena parte, la situación turística en la que se encuentre el destino dependerá de las circunstancias socioeconómicas existentes en el propio destino. De esta forma, se observó que el destino venía sufriendo una pérdida importante de población en los últimos 30 años, pasando de 9722 habitantes en 1981 a 6064 en el año 2011, según los censos de población realizados.

Además, se detecta que Almadén sufre un envejecimiento progresivo de su 
población, y un considerable aumento del desempleo desde el inicio de la crisis económica. En cuanto a los sectores de actividad económica, tiene especial importancia el sector servicios además del sector primario. En este sentido, y dadas la situación planteada, Almadén y su comarca se encuentran catalogados por la Junta de CastillaLa Mancha como una zona rural de alta prioridad para su desarrollo.

\subsection{Análisis de la oferta y los recursos turisticos del destino}

Adentrándonos plenamente en el análisis turístico, se realizó un estudio de los recursos y la oferta turística existente en el destino, a través de un proceso de valoración de los recursos turísticos. Dichos recursos fueron valorados según puntuaciones objetivas expuestas en cada una de las fichas de recursos elaboradas, las cuales quedaban agrupadas en recursos del núcleo de población y del propio Parque Minero, recursos de carácter inmaterial y recursos de tipo natural. El objetivo de toda esta labor reside en observar la situación de cada recurso y poder comparar entre unos y otros según su nivel de desarrollo y puesta en valor turística, tal y como se puede observar en los gráficos siguientes, referidos a los recursos principales del destino ${ }^{1}$ :
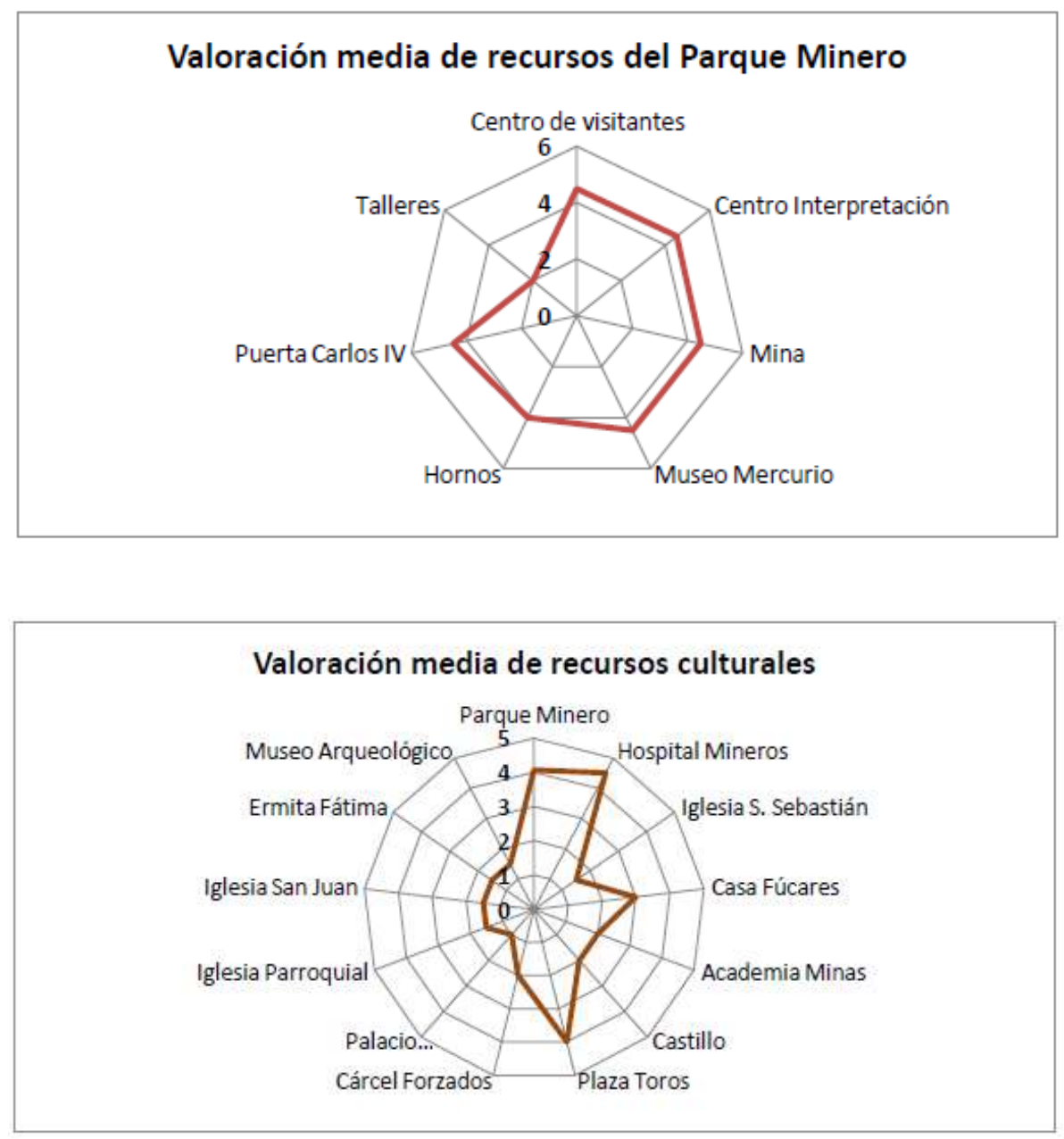

De esta forma, se obtuvo que la valoración que poseían los recursos integrados en el Parque Minero era mucho mayor que la del resto de recursos patrimoniales del casco

${ }^{1}$ : Gráficos con las valoraciones obtenidas por los principales recursos turísticos del Parque Minero y del casco histórico de Almadén, respectivamente. Elaboración propia. 
Azuara Grande, A. y del Río de la Hoz, I. (2016): “Análisis turístico de Almadén (Ciudad Real). Propuestas de mejora en un entorno Patrimonio de la Humanidad"

urbano de Almadén, salvo dos recursos: Hospital de Mineros y Plaza de Toros. Por tanto, existían en el destino notables diferencias entre la importancia turística de unos recursos y otros, impidiéndose el desarrollo turístico de forma homogénea a lo largo del destino, al encontrarse los puntos turísticos en zonas muy concretas y separadas entre sí en el territorio.
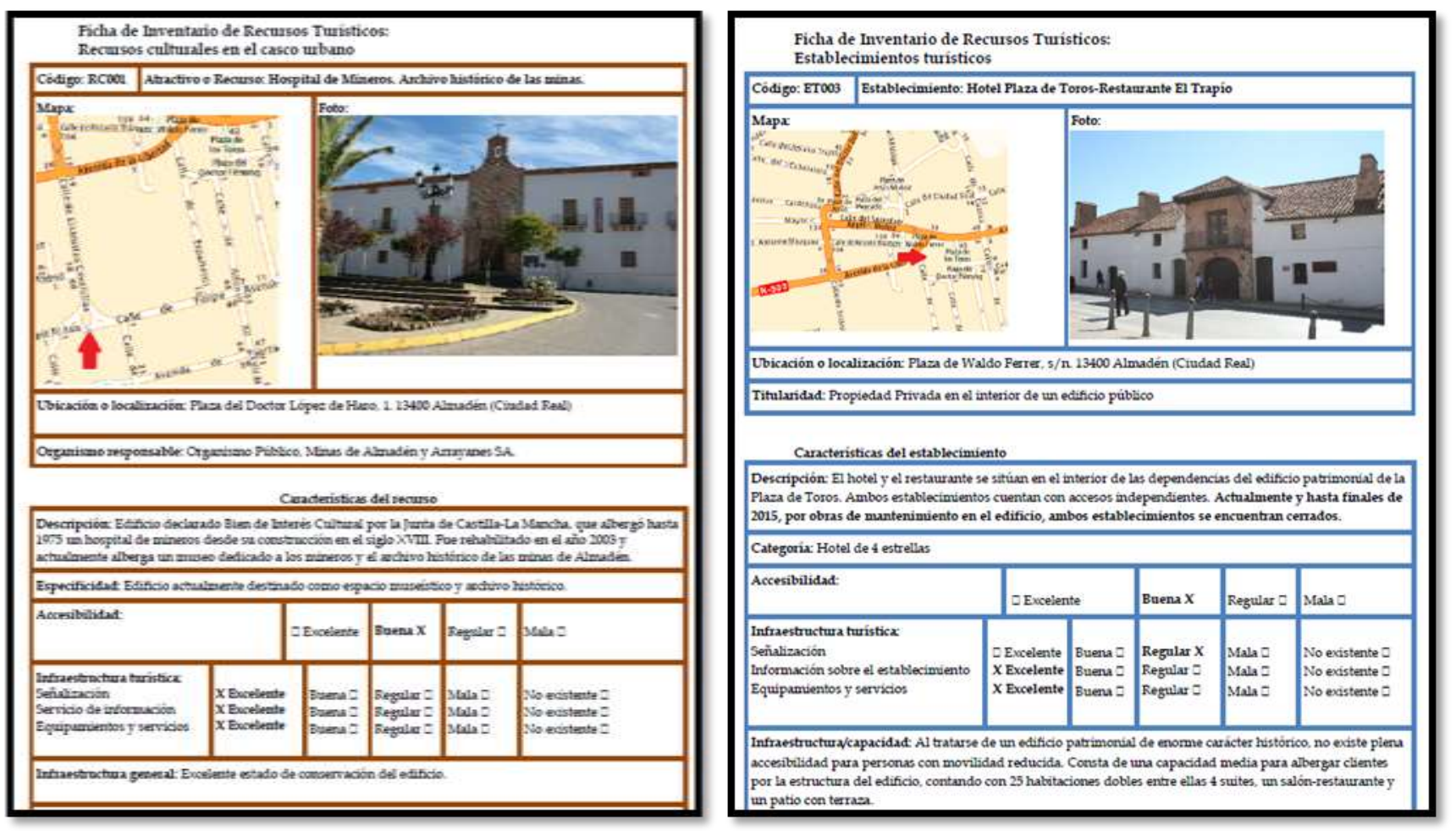

Por su parte, para el análisis de los establecimientos de oferta turística, el estudio contó con numerosas similitudes respecto al anterior, ya que también se emplearon fichas de recursos ${ }^{2}$ para su valoración, en este caso, adaptadas a los establecimientos turísticos. De esta forma, se dividió la oferta según establecimientos de alojamiento, restauración y otros tipos de oferta. El objetivo fue detectar patrones de accesibilidad a los establecimientos, estándares de calidad seguidos, número de oferta existente de cada tipo, entre otros aspectos.

\subsection{Análisis de la demanda turistica}

El siguiente estudio realizado fue el de la demanda turística, el cual tenía por objetivo detectar los perfiles de demanda del destino a través de las respuestas a los cuestionarios realizados a los agentes, así como analizar el número de visitantes registrados por el Parque Minero de Almadén. Respecto a los perfiles detectados por el análisis, fueron los siguientes: de forma mayoritaria, excursionistas, turismo familiar, y turismo mayor de 65 años. De forma minoritaria, visitas escolares y turistas extranjeros. Todos ellos poseen el rasgo común de la corta estancia de su visita (de 1 a 3 dias), y en el caso de los turistas nacionales, la procedencia mayoritaria de provincias y localidades cercanas, así como de Madrid y Cataluña. Respecto al nivel de gasto, se detectaron diferencias entre

2 : Ejemplos de fichas de recursos dedicadas a un recurso patrimonial (izda.) y a un establecimiento hotelero (dcha.), respectivamente. Elaboración propia. 
perfiles de gasto medio-bajo como los excursionistas, y perfiles de gasto medio y alto como el turismo familiar, mayor de 65 años y los extranjeros.

Por último, gracias a la información facilitada por el Parque Minero de Almadén, se obtuvo la evolución de los visitantes del mismo desde su apertura en 2006, obteniéndose un total de 3898 visitantes. Destaca el rápido incremento experimentado hasta el año 2008, cuando se alcanzaron 18.121 visitantes, y el posterior decrecimiento continuado a lo largo de los años desde ese mismo año, alcanzándose 10.190 visitantes en 2013, así como la pequeña recuperación de 2014, con 910.829 visitantes en total.

\subsection{Análisis de la funcionalidad turistica y estructura urbana del destino}

A continuación se procedió a analizar la funcionalidad turística y la estructura urbana del destino, a partir de tres aspectos fundamentales:

\section{-Accesibilidad del destino:}

- Análisis de la ubicación del destino respecto a los principales centros de emisión de turistas en España

-Accesos viarios al destino, y sus respectivas distancias a los principales centros emisores de turistas

-Presencia de redes de transporte público.

\section{-Infraestructuras, equipamientos y servicios:}

-Estado y características de las calles y vías urbanas

-Existencia de señalización del destino, tanto turística como a nivel general

-Presencia de zonas de aparcamiento, equipamiento cultural, zonas verdes, y mobiliario urbano existente.

\section{-Movilidad y capacidad de acogida del destino:}

- Existencia o no de recorridos turísticos establecidos para los turistas

-Organización de las visitas a los recursos turísticos.

\subsection{Análisis de los agentes turísticos del destino}

El siguiente análisis realizado para el destino fue el de los agentes turísticos de Almadén realizándose en primer lugar una descripción de las funciones y características principales de dichos agentes, seguido de un análisis de las respuestas a las entrevistas en profundidad realizadas a los dos actores principales, y de los cuestionarios al resto de agentes. El objetivo principal era realizar un análisis de las relaciones entre agentes y las redes formadas, a través de la dinámica relacional descrita en la metodología del trabajo.

De esta forma, se puso de manifiesto a través de las entrevistas realizadas que los acuerdos de colaboración existen y son frecuentes, aunque dichos acuerdos comunes resulten puntuales y se encuentren únicamente vinculados a la promoción del destino en su conjunto, dejando de lado otros aspectos como la gestión compartida público-

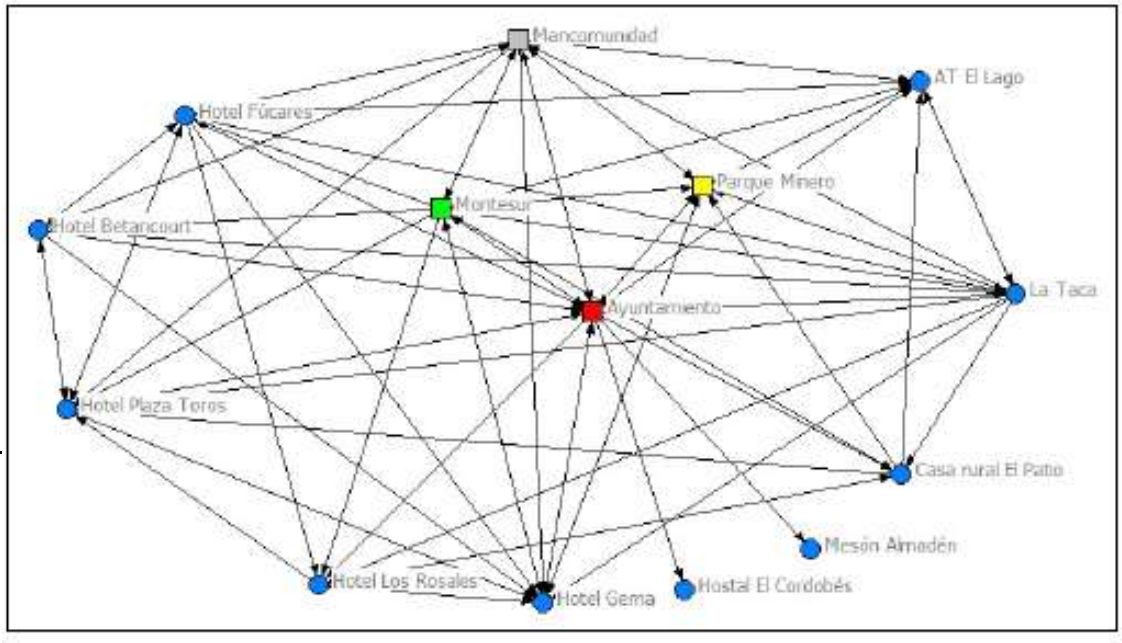
privada del destino. A partir de las respuestas a estas entrevistas y a los cuestionarios, se desarrolló el análisis de relaciones entre agentes mostrado en el 
gráfico $^{3}$, en el que se obtuvo la conclusión de que, a pesar de la densa red existente, sigue existiendo un actor central en el destino (Ayuntamiento), principal institución encargada de la toma de decisiones en materia turistica en el destino, junto con el resto de agentes públicos, a pesar de que uno de ellos (MAYASA-Parque Minero) se encuentre más aislado respecto al destino de lo que debería estarlo. En este sentido, a modo general, debe tratar de mejorarse la implantación de relaciones bilaterales entre los agentes turísticos para equiparar las relaciones de salida y entrada entre los propios integrantes, lo que permitirá crear una red sólida y continuada en el tiempo.

\subsection{Análisis de promoción, comercialización e imagen de marca del destino}

El último elemento del análisis interno fue el estudio de las labores de comercialización, promoción y marca del destino. Para ello, se analizó la presencia y alcance de las redes de turismo presentes en el destino, y los itinerarios culturales en Almadén, las marcas turísticas empleadas y su repercusión sobre el destino, así como la información del destino recogida en las páginas web y en las publicaciones turísticas emitidas por los agentes decisores del destino.

\section{RESULTADOS}

\subsection{Diagnóstico}

Tras desarrollar los análisis interno y externo al destino turístico, y a partir de todo lo expuesto se procede a realizar el diagnóstico de la situación actual en la que se encuentra actualmente el destino, especificando las amenazas y oportunidades concretas que plantea el entorno del destino, así como las debilidades y fortalezas existentes de forma intrínseca al destino, siguiendo el modelo del llamado "análisis DAFO".

\subsubsection{Amenazas y oportunidades}

Se han detectado tres amenazas claras al desarrollo turístico procedentes del entorno próximo de Almadén. En primer lugar, la elevada tasa de desempleo existente en la provincia de Ciudad Real y en toda Castilla-La Mancha, siendo de las más elevadas del país y la Unión Europea; en segundo lugar, los niveles de desarrollo económico, ya que Ciudad Real y a modo general, Castilla-La Mancha, se encuentra en términos de PIB per Cápita entre las regiones con menor desarrollo económico de España, lo que resulta una clara amenaza para el destino a la hora de pretender incrementar el desarrollo económico y empresarial en un entorno nada favorable; y por último, los niveles de desarrollo tecnológico, y a que Castilla-La Mancha cuenta con un desarrollo tecnológico notablemente inferior a la media nacional, lo que supone una problemática para el destino a la hora de implantar nuevas tecnologías para su uso turístico.

Por su parte, Las oportunidades que plantea el entorno próximo de Almadén tienen que ver con los recursos culturales y naturales, ya que Castilla-La Mancha posee, al igual que el Estado español en su conjunto, unas importantes riquezas culturales y naturales reconocidas algunas de ellas a nivel internacional que suponen un atractivo imprescindible para el desarrollo de actividades turísticas, circunstancia de la que el destino puede beneficiarse en materia de promoción, comercialización y difusión en su conjunto con las marcas "España" y "Castilla-La Mancha". En este sentido, la existencia dicho patrimonio necesita de unas figuras de protección que sean capaces de velar por

3: Red de relaciones entre agentes turisticos en Almadén.

Fuente: Elaboración propia a partir de UCINET 6 
Azuara Grande, A. y del Río de la Hoz, I. (2016): “Análisis turístico de Almadén (Ciudad Real). Propuestas de mejora en un entorno Patrimonio de la Humanidad"

su integridad. En este sentido, Castilla-La Mancha cuenta con legislación en este aspecto que ha sido actualizada recientemente, incorporándose nuevos conceptos y planteamientos que permiten en consecuencia la oportunidad de diversificar y adaptar la oferta turistica a los requerimientos de la demanda.

\subsubsection{Debilidades}

El grueso de los resultados obtenidos tiene que ver con la situación turística a nivel interno del destino, encontrándose un gran número tanto de debilidades como de fortalezas para su desarrollo turistico. Respecto a las primeras, la de mayor importancia tienen que ver con la coordinación entre agentes turísticos, ya que no existe una entidad u organismo que establezca y dirija la gestión turística general para el destino, existiendo varios actores públicos que colaboran entre si en materia de promoción y comercialización del destino. Asimismo, no se ha redactado un plan integral de gestión turística del destino, existiendo descoordinación y colaboración insuficiente del sector privado con el sector público, sectores con intereses diferentes, donde principalmente un agente público central impulsa las relaciones con el sector privado, no produciéndose relaciones bilaterales entre sí.

Por otro lado, el destino posee problemas estructurales de pérdida notable de población en las últimas tres décadas, tendiendo la población existente hacia el envejecimiento, dando lugar a la existencia de numerosos bienes inmuebles, principalmente viviendas, sin uso alguno en el destino. Esta situación produce en consecuencia una falta de tejido empresarial suficiente en el destino que provoca un elevado número de desempleados y falta de oportunidades para la población local.

Igualmente, Almadén se encuentra en una ubicación geográfica desfavorable y periférica respecto a los centros de mayor dinamismo económico y cultural de Castilla-La Mancha y de España, lo que provoca una situación de aislamiento del destino respecto a otros más próximos a estos centros urbanos de interés.

En otro punto, se han detectado claros problemas de comercialización del destino, los cuales son percibidos por los agentes turísticos, que observan como Almadén es actualmente un destino poco conocido, siendo la marca "Almadén" poco reconocida por los turistas. A pesar de la pertenencia del destino a determinadas redes de turismo (Red de Turismo Industrial, Red de Cuevas Turísticas) e itinerarios culturales (Camino Real del Azogue) que podrían mejorar la comercialización del destino, a la hora de la verdad no se reflejan a la vista de los turistas debido al escaso desarrollo y nula implantación en el propio destino.

Por último, se destaca importante debilidad la escasa oferta turistica de alojamiento y restauración en el destino, así como una práctica inexistencia de oferta de turismo rural, turismo activo y establecimientos complementarios, concentrada en torno a la localidad de Almadén y prácticamente inexistente en su comarca.

En adición, se han detectado en el destino otras debilidades que a pesar de resultar un impedimento para el desarrollo turístico, no resultan tan críticas como las anteriormente mencionadas. Entre ellas están los importantes conflictos entre los usos establecidos para peatones y vehículos en el casco histórico de Almadén; las notables diferencias existentes en el desarrollo turístico entre los recursos culturales, naturales e inmateriales del casco urbano respecto al Parque Minero, lugar turístico por excelencia del lugar; la insuficiencia y heterogeneidad de las informaciones recogidas por las estadisticas turisticas oficiales, así como de aspectos que tienen que ver con la señalización y la información turística, destacando la práctica inexistencia de señalización en inglés.

\subsubsection{Fortalezas}

A su vez, existen aspectos fundamentales que potencian el desarrollo turístico de 
Almadén. El más importante de todos ellos es su declaración como Patrimonio de la Humanidad, elemento que sirve de reconocimiento del destino a nivel nacional e internacional por sus valores únicos, siendo una distinción que otros destinos similares en España no poseen, y que permite atraer una demanda de mayor calidad, así como un mayor número de recursos económicos. Dicha declaración fue posibilitada gracias a un patrimonio minero único y muy atractivo para la actividad turística. Este patrimonio se encuentra en buen estado de conservación y ha sido en su mayoria puesto en valor tras unas importantes inversiones llevadas a cabo en la última década.

Por otra parte, el destino cuenta con recursos naturales atractivos y de gran valor ecológico, existiendo itinerarios con potencialidad alta para el turismo. La incorporación de este entorno natural a la Red Natura 2000 y la proximidad al Parque Natural de la Sierra de Alcudia, permiten el reconocimiento del destino a nivel nacional y europeo.

Respecto a las relaciones entre agentes turisticos, existe la fortaleza de poseer una densidad elevada en el número de relaciones establecidas entre agentes turísticos en el destino, destacando la actividad de una serie de agentes que inician un mayor número de relaciones y que son los verdaderos impulsores de la actividad turística.

Por último, se detecta la existencia en el destino de festividades celebradas en distintas épocas del año, circunstancia que podría evitar una hipotética estacionalización turística.

Igualmente existen otras fortalezas que aunque no resultan ser de igual importancia que las anteriormente mencionadas, también posibilitan un mejor desarrollo turístico para Almadén. Entre ellos está el buen estado de los accesos viarios a Almadén desde Ciudad Real y Madrid, con un potencial acceso de turistas desde Córdoba, ya que es la ciudad declarada Patrimonio de la Humanidad más cercana al destino; la existencia de señalización turística por todo el destino; una notable presencia en internet y redes sociales del destino y sus agentes turísticos, facilitando su promoción y difusión; la disponibilidad de alojamientos turísticos de cuatro estrellas; y la disponibilidad de suficientes espacios culturales que pueden ser empleados como complemento turístico, destacando la funcionalidad y la diversidad de usos que pueden contener estos espacios (Ejemplo de la escuela universitaria o la Plaza de Toros).

\subsection{Programa estratégico y de actuaciones para el destino}

Tras establecerse el diagnóstico del destino y comprender cuál es la situación vigente en la que se encuentra, finalmente se presentaron las estrategias turísticas que deberán llevarse a cabo en Almadén para poder plantear propuestas y actuaciones de mejora. El objetivo final pasaría por implantar modelos de gestión y planificación que consigan convertirlo en un importante destino de turismo cultural y natural centrado en la mineria, siempre incorporando a la propia población local como beneficiaria del desarrollo turístico emprendido.

- La primera línea estratégica se refiere a la coordinación y la gestión turística, que debe llevar incorporada las siguientes propuestas: Creación de unas comisiones de desarrollo turístico en las que participen todos los agentes que intervienen en el destino; plantear la creación de un ente de gestión turística conjunta para todo el destino, algo que se llevaría a cabo más a largo plazo: el impulso a la creación de organizaciones de empresarios y vecinos actualmente no existentes; la reasignación de competencias de la mancomunidad de la Comarca de Almadén, dotándola de mayores capacidades turísticas; proponer acuerdos de colaboración a otros destinos cercanos y vinculados con Almadén; y por último, diseñar un plan turístico anual para Almadén.

- Otra estrategia a desarrollar sería la relacionada con la oferta turistica y la mejora de sus niveles de calidad, lo que llevaria a proponer: la implantación de sistemas y/o certificados de calidad turística; extender la oferta turística a más municipios de la 
comarca de Almadén y crear oferta alternativa, especialmente establecimientos rurales y empresas organizadoras de actividades turísticas complementarias; y la creación y mejora de los itinerarios turísticos de Almadén y su comarca.

- Igualmente, debe seguirse también una estrategia para la demanda turística, que implicaría acciones de diversificación de la demanda turística y potenciación de aquellos perfiles más interesantes para el destino, así como la realización de estudios de demanda acerca de los turistas que visiten el destino.

- En relación a la mejora de los equipamientos y la movilidad de los turistas en el destino, la estrategia a seguir pasa por las siguientes propuestas: Establecer restricciones de tráfico en el casco histórico de Almadén; crear nuevas plazas de aparcamiento para turistas; y acondicionar nuevas zonas verdes y de esparcimiento para los turistas.

- La última estrategia a seguir, es la relacionada con la comercialización y promoción turística. Las propuestas planteadas tienen que ver con el impulso y consolidación de las redes de turismo e itinerarios culturales presentes en el destino. Por otro lado, deben hacerse mejoras en la gestión turística de los recursos naturales del entorno y fomentar el uso del transporte público por los turistas y crear productos turísticos a través del ferrocarril. Además es imprescindible crear un calendario anual de festividades y eventos turísticos. Finalmente, las últimas propuestas tienen que ver con la solución de problemas en la señalización turística y en la información del destino en internet, así como intentar plantear acuerdos de comercialización conjunta con otros destinos Patrimonio de la Humanidad del patrimonio minero e industrial en España y Europa.

\section{CONCLUSIONES}

A lo largo del trabajo, se demuestra cómo la evolución histórica de Almadén y sus explotaciones mineras han otorgado a este enclave una importancia cultural, social y económica a nivel mundial durante siglos, la cual ha sido reconocida recientemente mediante la declaración de Patrimonio de la Humanidad. A pesar de dicho reconocimiento, Almadén y su comarca se han visto envueltos en las últimas décadas en una serie de problemas estructurales derivados del cese de las explotaciones mineras e industriales relacionadas con el mercurio, que han llevado a este territorio a una situación límite por sobrevivir y continuar en su desarrollo. Es en este contexto, en el que el reconocimiento a nivel mundial a través de su patrimonio minero recuperado y puesto en valor, junto con sus inequívocos atractivos culturales y naturales, permite apostar por la actividad turística, la cual sin embargo, todavía se encuentra dando sus primeros pasos hacia la evolución y consolidación, existiendo aún mucho trabajo por delante.

En este sentido, todo el análisis desarrollado en el trabajo, con su posterior diagnóstico y propuestas estratégicas de actuación, ha mantenido en todo momento el objetivo de proporcionar una visión clarificadora de la situación turística de Almadén, con sus problemáticas y sus aspectos más consistentes, siendo todo ello es necesario para emprender definitivamente el desarrollo y consolidación turística del destino y su entorno.

En definitiva, desde el trabajo se ha pretendido que todas las líneas estratégicas puedan complementarse para instaurar un correcto desarrollo turístico en el que los esfuerzos estén orientados en la misma dirección y con la misma finalidad. De esta forma, se muestra el convencimiento de que todo aquello que se ha descrito en los contenidos del trabajo puede ser de gran utilidad para que los responsables turísticos del destino permitan mejorar la calidad de vida y las oportunidades de sus habitantes, asi como la difusión de los valores únicos y auténticos del legado cultural de Almadén a través del turismo, proporcionando a un lugar tan singular como éste la importancia que 
se merece.

\section{BIBLIOGRAFÍA}

Benito del Pozo, P., (2012): "Territorio, paisaje y herencia industrial: debates y acciones en el contexto europeo.” Documents d'Anàlisi Geogràfica vol. 58/3, pp. 443-457.

Biel-Ibáñez, P., (2009): "El paisaje minero en España como elemento de desarrollo territorial.” Apuntes vol. 22 núm. 1, pp. 6-19, ISSN: 1657-9763.

Cañizares Ruiz, M.C., (2008): "El atractivo turístico de una de las minas de mercurio más importantes del mundo: El Parque Minero de Almadén (Ciudad Real)." Cuadernos de Turismo, $\mathrm{n}^{\circ}$ 21, pp. 9-18. ISSN: 1139-7861.

Cañizares Ruiz, M.C., (2010): "Patrimonio minero y territorio en la Borgoña francesa. El "Museo de la mina" de Blanzy." De Re Metallica, 14, pp. 13-22. ISSN: 1577-9033.

Cañizares Ruiz, M.C., (2011): "Protección y defensa del patrimonio minero en España.” Scripta Nova, vol. 15, núm. 361. ISSN: 1138-9788.

Cañizares Ruiz, M.C., (2011): "Patrimonio, parques mineros y turismo en España." Cuadernos de Turismo, n 27, pp. 133-153. ISSN: 1139-7861.

Cañizares Ruiz, M.C., (2013): "Patrimonio, Mineria y Rutas en el Valle de Alcudia y Sierra Madrona (Ciudad Real).” Estudios Geográficos Vol. LXXIV, 275, pp. 409-437. ISSN: 0014-1496.

Carrasco Milara, F.J., (2009): Las Minas de Almadén. Historia Reciente. Minas de Almadén y Arrayanes S.A., Fundación Almadén-Francisco de Villegas, Ciudad Real. Moscú, Rusia.

Carta de Nizhny Tagil sobre el Patrimonio Industrial, (2003). TICCIH, ICOMOS,

Fernández Ochoa, C., Zarzalejos Prieto, M., (2010): “¿Sísapo en La Bienvenida (Ciudad Real)? De nuevo sobre la radicación geográfica y el estatuto jurídico de la capital del cinabrio hispano." Arqueología, sociedad, territorio y paisaje: Estudios sobre prehistoria reciente, protohistoria y transición al mundo romano. CSIC, Instituto de Historia. Madrid.

Foronda Robles, C., García López, A., (2008): "Capital social y gobernabilidad en el turismo minero de Riotinto." Proyecto nacional I+D "Análisis Territorial del Capital Social en Espacios Naturales Protegidos: Indicadores de desarrollo socioeconómico", Ministerio de Ciencia e Innovación.

García Delgado, F.J., Delgado Dominguez, A., Felicidades García, J. (2013): “El turismo en la Cuenca Minera de Riotinto." Cuadernos de Turismo, n ${ }^{\circ}$ 1, pp. 129-152. ISSN: $1139-7861$.

García Hernández, M., (2007): "Entidades de planificación y gestión turística a escala local. El caso de las ciudades Patrimonio de la Humanidad de España." Cuadernos de Turismo, no 20, pp. 79-102, ISSN 1139-7861.

Hortelano Mínguez, L.A., (2011): "Turismo minero en territorios en desventaja geográfica de Castilla y León: recuperación del patrimonio industrial y opción de desarrollo local." Cuadernos de Turismo $\mathrm{n}^{\circ}$ 27, pp. 521-539, ISSN 1139-7861.

Lang, M.F., (1994): "El Azogue de Almadén: Su empaque y conducción a Sevilla." Hispania, LIV/1, núm. 186, pp. 95-110. 
López-Morell, M. A., (2008): "La comercialización del mercurio de Almadén durante el siglo XIX y el primer tercio del siglo XX." Boletín Geológico y Minero, 119 (3): 309-330 ISSN: 0366-0176.

Matilla Tascón, A., (1958). Historia de las Minas de Almadén Vol. I: Desde la época romana hasta el año 1645. Consejo de Administración de las Minas de Almadén y Arrayanes, Madrid.

Matilla Tascón, A., (1987). Historia de las Minas de Almadén Vol. II: Desde 1646 a 1799. Minas de Almadén y Arrayanes S.A, Madrid.

Merinero Rodríguez, R., Pulido Fernández, J.I., (2009): "Desarrollo turístico y dinámica relacional. Metodología de análisis para la gestión activa de destinos turísticos." Cuadernos de Turismo n 23, pp. 173-193, ISSN: 1139-7861.

Nared, J. et. al., (2013): "Including development topics in a cultural heritage management plan: Mercury Heritage in Idrija." Acta Geographica Slovenica, 53-2, pp. 393402.

Plan Estratégico de Turismo de Castilla-La Mancha 2010-2014. Vicepresidencia y Consejería de Economía y Hacienda, Junta de Comunidades de Castilla-La Mancha.

Poria, Y., Reichel, A., Cohen, R., (2012): "Tourists perceptions of World Heritage Site and its designation." Tourism Management 35 pp. 272-274.

Puche Riart, O., Hervás Exojo, A., Mazadiego Martínez, L., (2011): “ El patrimonio histórico minero-metalúrgico en España: su impacto en el turismo cultural." De Re Metallica, 17, pp. 27-46. ISSN: 1888-8615.

Rojas Ávalos, A., (2013). Patrimonio del Mercurio. Basado en el expediente de nominación a la Lista del Patrimonio Mundial. Fundación Almadén-Francisco de Villegas, Ayuntamiento de Almadén, Ciudad Real.

Sancho Comíns, J., Panadero Moya, M., (dirs.) (2004): Atlas del Turismo Rural de Castilla-La Mancha. Dirección General del Instituto Geográfico y Catastral, Madrid, pp. 188-189, 210-211, 256-263.

United Nations Educational, Scientific and Cultural Organization, (2012): Convention concerning the protection of the World Cultural and Natural Heritage. Decision 36 COM 8B.39. World Heritage Committee. Thirty-sixth Session, Saint Petersburg, Russian Federation.

Valenzuela Rubio, M., Palacios García, A.J., Hidalgo Giralt, C. (2008): "La valorización turística del patrimonio minero en entornos rurales desfavorecidos. Actores $y$ experiencias." Cuadernos de Turismo, n 22, pp. 231-260. ISSN: 1139-7861.

Zarzalejos Prieto, M., (1994): "La búsqueda de Sísapo: hipótesis sobre la reducción geográfica de la capital del cinabrio hispano." Espacio, tiempo y forma, Serie II, Historia Antigua, L 7, págs. 175-191.

\section{HOW TO CITE THIS ARTICLE IN BIBLIOGRAPHIE}

Azuara Grande, A. y del Río de la Hoz, I. (2016): "Análisis turístico de Almadén (Ciudad Real). Propuestas de mejora en un entorno Patrimonio de la Humanidad" Rotur. Revista de Ocio y Turismo, 11: 22-34, ISSN-e 2695-6357 DOI: https:// doi.org/10.17979/rotur.2016.11.1.1778 